\title{
Dilemma in the Management of Duchenne Muscular Dystrophy in a Resource Limited Settings
}

\author{
Usman AB ${ }^{1}$, Emmanuel P², Onimisi EO ${ }^{3}$, Oyinloye $\mathrm{OA}^{4}$, Nachanuya A $^{5}$, Abubakar MA ${ }^{6}$, Nggada HA7
}

\begin{abstract}
Duchene muscular dystrophy is an $\mathrm{x}$-linked recessive genetic disorder which present with progressive muscle weakness in children. It is often complicated by child becoming wheelchair bound by age 12 . This limitation on the child and lack of cure is a great burden on the child, family and the community. We present a case of an 11-year old boy who presented with a seven years history of progressive limb weakness. Examination revealed hyper-lordosis of the thora-columbar spine, hypertrophied calf muscles, weak lower limbs and waddling gait. Due to financial constraint, only histology was relied on for definitive diagnosis. He was counselled, placed on prednisolone and commenced physiotherapy. This case portrays the challenges associated with the management of a rare disease in resource constraint settings.
\end{abstract}

Key words: Duchene Muscular dystrophy, Nigeria, Children

\section{Introduction}

$\mathrm{M}$ uscular dystrophies are a conglomerate of genetic disorders characterized by weakness and wasting of muscle ${ }^{1}$. Duchene muscular dystrophy (DMD) is an X-linked recessive disorder affecting 1 in every 3500-5000 males globally ${ }^{2}$. It results from mutations in the DMD gene which encodes the membrane-associated dystrophin protein $^{3}$. It is a musculoskeletal disorder which manifests with a progressive muscular weakness and pathologic features of fibrosis and fatty replacement ${ }^{4}$. The progressive deterioration in the normal function results in a wide spectrum of physical and psychosocial consequences to both patient and caregivers ${ }^{5}$ especially as muscle wasting progresses from 3 to 5 years with associated delayed motor development ${ }^{4}$.

Management of DMD in resource constraint settings presents a monumental challenge. We report a case of DMD managed in a resource constraint setting.

\section{The Case}

Our patient is an 11-year-old male who presented at the outpatient clinic of Federal Medical Centre Yola, Adamawa State, Nigeria with a seven year history progressive weakness of the limbs and abnormal manner of walking. He gradually experienced progressive
${ }^{1}$ Dr. Ahmadu Baba Usman, MBBS, MHPM, FMCPaed, Department of Paediatrics, Federal Medical Centre Yola. Adamawa State Nigeria. ${ }^{2}$ Dr. Pembi Emmanuel, MBBS, Adamawa State Ministry of Health, Yola. Adamawa State, Nigeria, ${ }^{3}$ Dr. Ovansa Emmanuel Onimisi, MBBS, Department of Paediatrics, Federal Medical Centre Yola. Adamawa State Nigeria. ${ }^{4} \mathrm{Dr}$. Adewale O Oyinloye, MBBS, FWACS, Department of Surgery, Federal Medical Centre Yola, Nigeria, ${ }^{5} \mathrm{Dr}$. Apollos Nachanuya, MBBS, Department of Paediatrics, Federal Medical Centre Yola. Adamawa State Nigeria, ${ }^{6}$ Dr. Auwal M Abubakar, MBBS, FWACS, FICS, Department of Surgery, Federal Medical Centre Yola, Nigeria, ${ }^{7}$ Dr. Haruna A Nggada, MBBS, FMCPath, Department of Laboratory Services, Histopathology Unit, University of Maiduguri Teaching Hospital, Maiduguri, Borno State, Nigeria.

\section{Address for correspondence \\ Dr. Pembi Emmanuel \\ E-mail: gojiyavandua@gmail.com}

\section{How to cite}

Usman AB, Emmanuel P, Onimisi EO, Oyinloye OA, Nachanuya A, Abubakar MA, Nggada HA. Dilemma in the Management of Duchenne Muscular Dystrophy in a Resource Limited Setting. J Nepal Paediatr Soc 2018;38(2):122124.

doi: http://dx.doi.org/10.3126/jnps.v38i2.19623

This work is licensed under a Creative Commons Attribution 3.0 License. 
difficulty in getting up from sitting and lying positions, awkward manner of walking or running and frequent fall while standing or walking. He also experienced easy fatigability and body weakness. As the condition worsened, medical intervention was sought for in various peripheral medical centers by the parents but no significant relieve of symptoms was achieved before coming to our facility.

$\mathrm{He}$ is the only male child amongst His mother's three children who were all born in a monogamous setting. He experienced a delayed developmental milestone during which he achieved head control at the first year, crawled at the second year and walked only at the third year.

Other history related to pregnancy such as febrile illness, abnormal vaginal discharge, vaginal itch, vaginal bleeding or taking of un-prescribed medications experienced by the mother during gestation was uneventful. Both mother and the patient were fully immunized.

On examination, he was not pale, afebrile, not icteric, not cyanosed, not dehydrated with no pedal oedema. He had hyper lordosis of the thoracolumbar spine as shown in Figure 1. Both his lower limbs were weak with associated waddling gait. The calf muscles were hypertrophied as shown in Figure 1 and GOWER'S SIGN was POSITIVE. There was no joint swelling or tenderness. He was fully conscious but sluggish. He was oriented in Time Person and Place. He had a normal skull but had an abnormal Curvature (hyper lordosis) of spine and hypertonia of the lower limbs. The tone in the upper limbs were however normal. A power of $4 / 5$ was measured for the upper limb and $3 / 5$ for the lower limb. There were normal reflexes in both upper and lower limbs. He walked with a waddling gait but no other cerebellar dysfunctions were noticed. His Pulse Rate was $110 \mathrm{bpm}$. There were normal first and second heart sounds with no murmurs. Other systems were however stable. A presumptive diagnosis of suspected cases of Duchene muscular dystrophy and Ankylosis spondylitis were first made and an X-ray of the thoracolumbar spine, Calf muscle biopsy and Serum creatinine kinase were requested. Due to financial constraint, only biopsy of the calf muscle was undertaken. The biopsy result revealed sections of tissue composed of skeletal muscles with endomysial connective tissue proliferation and scattered degeneration. The muscle tissue was replaced with fibro connective tissue as shown by the arrow in Figure 3 . With these histologic features, history and examination, a diagnosis of Duchene muscular dystrophy was made. Supportive management including counselling, physiotherapy and prednisolone tablet was commenced on outpatient basis, and he was scheduled for follow up appointment. However, the patient did not come back for follow up visit despite numerous phone call appeals.

\section{Informed consent}

The patient and the care giver have consented to every aspect of the patient management including using the case for academic purposes and teachings.

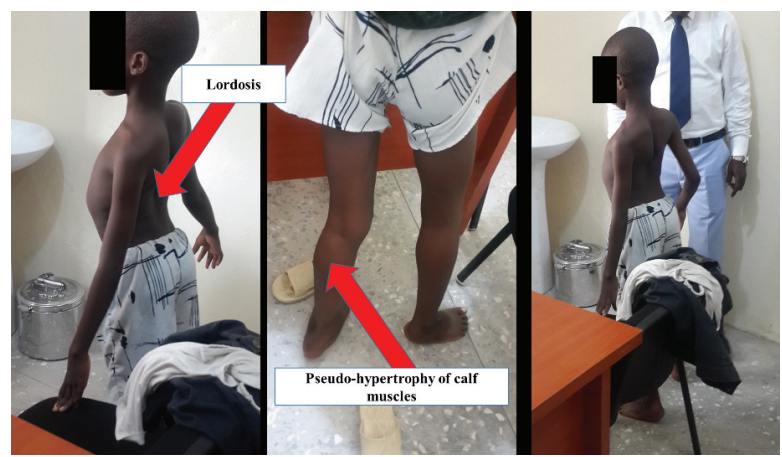

Fig 1: A photography of the child showing A. Lordosis, B. Pseudo-hypertrophy of the calf muscles as shown by the red arrows.

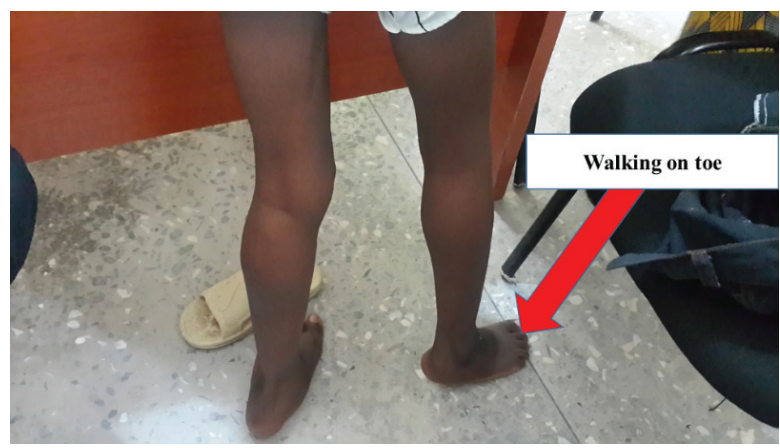

Fig 2: A photograph showing child toe-walking

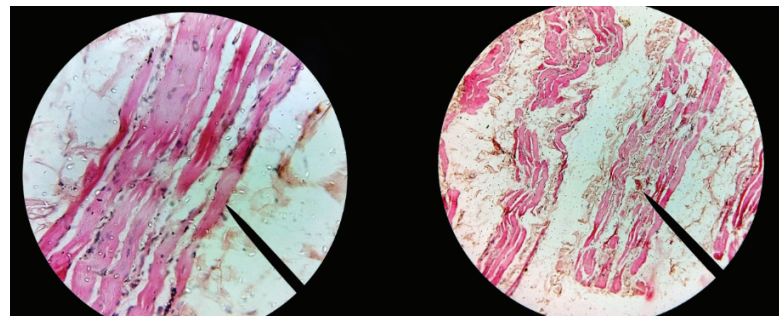

Fig 3: Histology result from biopsy of the calf muscle. The arrow shows progressive loss of muscle fibres and their replacement by fat and connective tissue

\section{Discussion}

Though the genetic basis and molecular mechanisms underlying DMD have been extensively investigated no effective treatment exists till today ${ }^{1}$. Current therapy is centered on use of glucocorticoids and physiotherapy to ameliorate complications ${ }^{6}$. Improved quality of life, function and longevity have 
been attained through multidisciplinary approach? Since lack of specific treatment for DMD is one of the challenges of this disease and its management being usually supportive, in our setting, the supportive management offered in developed countries are lacking. Usually treatment is channeled towards management of complications such as cardiac failure, arrythmias etc. Physiotherapy is centered towards helping the patients to cope with their disability. Our facility lacks this multidisciplinary management. Patients in poor setting find it hard to afford the available management as seen from Owerri, Imo state ${ }^{8}$. Management of DMD continues to evolve through emphasis on diagnosis ${ }^{9}$. These are not readily obtainable in resource constraint settings. The presentation of this index case, that of 12 year old boy to Federal medical centre Oweri and eleven patients from Ibadan reveals the existence DMD in Nigeria and need to not miss the diagnosis of $\mathrm{DMD}^{8,10}$. It is difficult to obtain an accurate information on the incidence of this disease and to ensure its early recognition in resource constraint areas because of the shortage of medical staff, particularly of specialist and the predominantly limited diagnostic facilities ${ }^{10}$. Though current care has been enhanced by the availability of more sensitive diagnostic techniques ${ }^{11}$, our patient was however accurately diagnosed through careful history, physical examination and histology.

\section{References}

1. Goyenvalle A, Seto JT, Davies KE, Chamberlain J. Therapeutic approaches to muscular dystrophy. Human Mol Genet 2011;20(R1):R69-78. DOI: 10.1093/ hmg/ddr105

2. Randeree L, Eslick GD. Eteplirsen for paediatric patients with Duchenne muscular dystrophy: A pooledanalysis. J Clin Neurosci 2018;49:1-6. DOI: 10.1016/j. jocn.2017.10.082

3. Crispi V, Matsakas A. Duchenne muscular dystrophy: genome editing gives new hope for treatment. Postgraduate Med journal 2018; 94(1111):296-304. DOI: $10.1136 /$ postgradmedj-2017-135377

4. Suneja B, Suneja ES, Adlakha VK, Chandna P. A Rare Case Report of Neurodegenerative Disease: Duchenne Muscular Dystrophy in Two Male Siblings. Int J Clin Pediatr Dent 2015;8(2):163-5. DOI: 10.5005/ jp-journals-10005-1306

5. Baiardini I, Minetti C, Bonifacino S, Porcu A, Klersy C, Petralia P, et al. Quality of life in Duchenne muscular dystrophy: the subjective impact on children and parents. J Child Neurol 2011;26(6):707-13. DOI: $10.1177 / 0883073810389043$

6. Venugopal V, Pavlakis S. Duchenne Muscular Dystrophy. StatPearls. Treasure Island FL: StatPearls Publishing LLC.; 2018.
Biopsy result is consistent with the usual findings in DMD in which there is proliferation of endomysial connective tissue, scattered degeneration, regeneration of myofibre, muscle fibre necrosis and replacement of muscle with adipose tissue and fat ${ }^{6}$. Other investigations such as electromyography and gene Analysis were not carried. Considering their economic hardship, investigations such as echocardiogram and ECG which may assist in management were not requested.

Sparing of His cognition is in keeping with DMD in which only 20 to 30 percent of patients have IQ less than $70^{6}$. Most patient with DMT usually experience depression and social isolation due to limitation of routine function posed by the clinical condition which hinders them from playing with their pairs ${ }^{8}$.

\section{Conclusion}

DMD, a rare disease presents a big challenge in its diagnosis and management in resource constraint settings. However, if doctors are acquainted with the clinical history and physical features in the presentation of DMD, they can make an accurate diagnosis through focused investigation. The actual incidence of DMD in Nigeria is not known, and there is probability that cases exists and are missed due to unfamiliarity with this rare disease.

7. Birnkrant DJ, Bushby K, Bann CM, Apkon SD, Blackwell $A$, Colvin MK, et al. Diagnosis and management of Duchenne muscular dystrophy, part 3: primary care, emergency management, psychosocial care, and transitions of care across the lifespan. Lancet Neurol 2018 Feb 1. page no; 445-455 DOI:10.1016/S14744422(18)30026-7

8. Odinaka KK, Nwolisa EC. Challenges in the management of the child with Duchenne muscular dystrophy in a resource poor setting:a case report. Pan Afr Med J 2014;19:227. DOI:10.11604/ pamj.2014.19.227.3137

9. Birnkrant DJ, Bushby K, Bann CM, Apkon SD, Blackwell $A$, Brumbaugh $D$, et al. Diagnosis and management of Duchenne muscular dystrophy, part 1: diagnosis, and neuromuscular, rehabilitation, endocrine, and gastrointestinal and nutritional management. Lancet Neurol 2018;17(3):251-67. DOI:10.1016/S14744422(18)30024-3

10. Dada TO, Elliott BA. Muscular dystrophy of Duchenne type in Nigerians. J Neurol Sci 1967;4(3):435-44. DOI: ?? DOI:10.1016/0022-510X(67)90028-7

11. Birnkrant DJ, Bushby K, Bann CM, Alman BA, Apkon $S D$, Blackwell $A$, et al. Diagnosis and management of Duchenne muscular dystrophy, part 2: respiratory, cardiac, bone health, and orthopaedic management. Lancet Neurol 2018;17(4):347-61. DOI: 10.1016/ S1474-4422(18)30025-5 